\title{
Collapsin response mediator protein 4 enhances the radiosensitivity of colon cancer cells through calcium-mediated cell signaling
}

\author{
SANG YOON PARK ${ }^{1 *}$, JONG-TAE KIM ${ }^{1 *}$, EUN SUN PARK ${ }^{1}$, YO SEP HWANG ${ }^{1}$, \\ HYANG RAN YOON $^{1}$, KYOUNG EUN BAEK ${ }^{1}$, HAIYOUNG JUNG ${ }^{1}$, SUK RAN YOON ${ }^{1}$, \\ BO YEON KIM ${ }^{2,3}$, HEE JUN CHO ${ }^{1}$ and HEE GU LEE ${ }^{1,3}$ \\ ${ }^{1}$ Immunotherapy Research Center, ${ }^{2}$ Anticancer Agent Research Center, Korea Research Institute of \\ Bioscience and Biotechnology (KRIBB), Daejeon 34141; ${ }^{3}$ Department of Biomolecular Science, \\ University of Science and Technology (UST), Daejeon 34113, Republic of Korea
}

Received September 8, 2020; Accepted December 18, 2020

DOI: $10.3892 /$ or.2021.7957

\begin{abstract}
Radiation therapy is an effective treatment against various types of cancer, but some radiation-resistant cancer cells remain a major therapeutic obstacle; thus, understanding radiation resistance mechanisms is essential for cancer treatment. In this study, we established radiation-resistant colon cancer cell lines and examined the radiation-induced genetic changes associated with radiation resistance. Using RNA-sequencing analysis, collapsin response mediator protein $4(C R M P 4)$ was identified as the candidate gene associated with radiation sensitivity. When cells were exposed to radiation, intracellular $\mathrm{Ca}^{2+}$ influx, collapse of mitochondrial membrane potential, and cytochrome $c$ release into the cytosol were increased, followed by apoptosis induction. Radiation treatment- or $\mathrm{Ca}^{2+}$ ionophore A23187-induced apoptosis was
\end{abstract}

Correspondence to: Dr Hee Gu Lee or Dr Hee Jun Cho, Immunotherapy Research Center, Korea Research Institute of Bioscience and Biotechnology (KRIBB), 125 Gwahak-ro, Yuseong-gu, Daejeon 34141, Republic of Korea

E-mail: hglee@kribb.re.kr

E-mail: hjcho@kribb.re.kr

${ }^{*}$ Contributed equally

Abbreviations: $\quad$ BAPTA-AM, 1,2-bis(2-aminophenoxy) ethane-N,N,N',N'-tetraacetic acid tetrakis(acetoxymethyl ester); CRMP4, collapsin response mediator protein 4; DPYSL3, dihydropyrimidinase-like protein 3; DHPase, dihydropyrimidinase; MMP, mitochondrial membrane potential; MPT, mitochondrial permeability transition; siRNA, small-interfering RNA; shRNA, short hairpin RNA; WST, water-soluble tetrazolium; PARP, polyADP-ribose polymerase; RIPA, radioimmunoprecipitation assay; DiOC6(3), 3,3'-dihexyloxacarbocyanine iodide; CsA, cyclosporin A

Key words: CRMP4, radioresistance, colon cancer, calcium influx, mitochondrial membrane potential significantly inhibited in CRMP4-deficient cells, including radiation-resistant or $C R M P 4$-shRNA cell lines. Furthermore, treatment of $C R M P 4$-deficient cells with low levels $(<5 \mu \mathrm{M})$ of BAPTA-AM, a $\mathrm{Ca}^{2+}$ chelator, resulted in radiation resistance. Conversely, $\mathrm{Ca}^{2+}$ deficiency induced by a high BAPTA-AM concentration $(>10 \mu \mathrm{M})$ resulted in higher cell death in the CRMP4-depleted cells compared to CRMP4-expressing control cells. Our results suggest that $C R M P 4$ plays an important role in $\mathrm{Ca}^{2+}$-mediated cell death pathways under radiation exposure and that CRMP4 may be a therapeutical target for colon cancer treatment.

\section{Introduction}

During cancer treatment, radiotherapy is used in conjunction with surgery to reduce recurrence and the risk of metastasis $(1,2)$. Although radiotherapy is a suitable treatment strategy for many cancer patients, the persistence of radiation-resistant tumor cells often poses a significant obstacle to effective radiation-based therapy and leads to poor prognosis (3). Thus, understanding the mechanisms governing radiation resistance is essential in enhancing the utility of radiotherapy.

Collapsin response mediator protein 4 (CRMP4), one of the five members of the cytosolic phosphoprotein family, is also known as dihydropyrimidinase-like protein 3 (DPYSL3) and shares $58 \%$ sequence homology with dihydropyrimidinase (DHPase) (4). DHPase catalyzes the ring-opening of 5,6-dihydrouracil to $\mathrm{N}$-carbamyl- $\beta$-alanine and that of 5,6 -dihydrothymine to $\mathrm{N}$-carbamyl- $\beta$-amino isobutyrate; however, whether CRMP4 demonstrates DHPase-like properties remains to be elucidated (5). In contrast to the structure of DHPase, CRMPs have a positively charged C-terminal that renders them highly susceptible to proteolysis (6). The C-terminal region of CRMP4 has been associated with neuronal cell injury and neurite damage (7). CRMP4 deletion in vivo exerts a neuroprotective effect against spinal cord injury owing to decreased apoptotic cell death rate and suppressed inflammatory responses (8). CRMP4 is thus considered an important therapeutic target for neuroregeneration. In addition, several 
studies have indicated that CRMP4 is involved in various types of cancers. For example, pancreatic and colon cancers show elevated CRMP4 expression, which strongly correlates with severe venous invasion, liver metastasis, and poor prognosis $(9,10)$. Conversely, CRMP4 is regarded as a metastasis suppressor in prostate and breast cancer $(11,12)$. These results indicate that a deeper analysis of CRMP4 function may offer new insights into potential cancer therapies.

The mitochondrial membrane potential (MMP) is the major component of the proton-motive force, which is the central intermediate of aerobic energy production and the driving force behind other physiological processes in the mitochondria, such as $\mathrm{Ca}^{2+}$ uptake and antioxidant activity (13). Cellular injury or stress stimulation directly elicits alterations in the mitochondrial architecture, membrane potential, and oxidative capacity, which are associated with an irreversible loss of mitochondrial matrix contents and integral membrane protein constituents, such as cytochrome $c$ oxidase (14). The release of cytochrome $c$ from the mitochondria leads to the activation of caspase- 3 and caspase-9, resulting in apoptosis (15). $\mathrm{Ca}^{2+}$ ions serve as an important second messenger for multiple physiological processes. Several studies have indicated that intracellular $\mathrm{Ca}^{2+}$ levels are regulated by ionizing radiation (16); moreover, the rise in intracellular $\mathrm{Ca}^{2+}$ levels after radiation exposure is crucial for a diverse array of signaling pathways that regulate critical cellular processes, including apoptosis $(17,18) . \mathrm{Ca}^{2+}$ influx has been known to be facilitated by voltage- and ligand-gated $\mathrm{Ca}^{2+}$ channels Although CRMP4 has not been reported to be associated with $\mathrm{Ca}^{2+}$ channels, CRMP2 was shown to interact with a novel $\mathrm{N}$-type voltage-gated $\mathrm{Ca}^{2+}$ channel $(19,20)$; nevertheless, the functional role of $\mathrm{Ca}^{2+}$ binding to CRMPs remains elusive.

In the present study, radiation-resistant colon cancer cell lines were established, and RNA sequencing was conducted to examine the radioresistant-associated genes. CRMP4 was identified as one of the strongly downregulated genes $(<0.5$-fold $)$ in the radioresistant cells compared to their parental cells. To know the function of CRMP4 under radiation exposure, MMP and cytochrome $c$ release were analyzed using CRMP4-knockdown SW620-shCRMP4 and RKO-shCRMP4 cells and radiation-resistant IR-SW620 and IR-RKO cells. In addition, $\mathrm{Ca}^{2+}$ ionophore $\mathrm{A} 23187$ and $\mathrm{Ca}^{2+}$ chelator BAPTA-AM were used to examine the relationship between CRMP4, $\mathrm{Ca}^{2+}$-related MMP, and apoptosis.

\section{Materials and methods}

Cell culture. Colon cancer cell lines SW480 (KCLB-10228; colon adenocarcinoma), SW620 (KCLB-10227; colorectal carcinoma), HT-29 (KCLB-30038; rectosigmoid colon adenocarcinoma), DLD1 (KCLB-10221; colon adenocarcinoma), Caco2 (KCLB-30037.1; colon adenocarcinoma), LoVo (KCLB-10229; colon adenocarcinoma, KM12C (KCLB-80015; colon carcinoma), and KM12SM (KCLB-80016; colon carcinoma) cells were purchased from the Korean Cell Line Bank (Seoul, Korea). RKO (ATCC CRL-2577; colon carcinoma), HCT116 (ATCC CCL-247; colorectal carcinoma), and LS174T (ATCC CL-188; colorectal adenocarcinoma) cells were purchased from the American Type Culture Collection (ATCC, USA). Each cell line was authenticated through
STR profiling from the cell line bank. Cells were cultured in Dulbecco's modified Eagle's medium (DMEM) (Gibco; Thermo Fisher Scientific, Inc.) supplemented with $10 \%$ fetal bovine serum (FBS) (HyClone) and $100 \mu \mathrm{g} / \mathrm{ml}$ antibiotics [100 U/ml penicillin and $100 \mu \mathrm{g} / \mathrm{ml}$ streptomycin (Gibco; Thermo Fisher Scientific, Inc.)] at $37^{\circ} \mathrm{C}$ under an atmosphere of $5 \% \mathrm{CO}_{2}$ in a humidified incubator.

Radiation exposure and radioresistant cell line generation. For radiation treatment, cells were seeded in 60-mm dishes and exposed to radiation from a ${ }^{60} \mathrm{Co}$ source (model 109 irradiator; JL Shepherd and Associates) at the indicated doses (0-5 Gy). Subsequently, cells were incubated at $37^{\circ} \mathrm{C}$ under a humidified, $5 \% \mathrm{CO}_{2}$ /air atmosphere. To generate radiation-resistant colon cancer cell lines $(21,22)$, cells (SW620, RKO, SW480, and HT-29) were plated in 60-mm dishes at a density of $5 \times 10^{3}$ cells/dish and exposed to a 5-Gy dose of ionizing radiation, followed by a 15 -day recovery period. This process was repeated for 24 treatment cycles totaling $120 \mathrm{~Gy}$; finally, radioresistant IR-SW620, IR-RKO, IR-SW480, and IR-HT-29 cell lines were established.

RNA sequencing and data analysis. The mRNAs of the established radioresistant IR-SW620, IR-SW480, IR-RKO, and IR-HT-29 cells were extracted using TRIzol (Sigma-Aldrich; Merck KGaA) method. The total RNA quantity and integrity of each RNA sample were evaluated using the bioanalyzer 2100 (Agilent Technologies, Inc.). The RNA concentration was quantified as $1 \mu \mathrm{g} / \mu \mathrm{l}$, rRNA ratio $(28 \mathrm{~S} / 18 \mathrm{~S})$ was 2.0 , and the RIN number was 10 (HT-29, RKO, IR-RKO, SW480, IR-SW480, SW620) and 9.9 (IR-HT-29, IR-SW620). The RNA sequencing library was prepared using the TruSeq RNA Sample Prep Kit (Illumina, Inc.) and sequenced using Hiseq-2000 (Illumina, Inc.) to generate 76- or 101-bp paired-end reads. Reads were trimmed to remove adapter sequences and base with low sequencing quality (per-base quality <20) using Cutadapt (23). The clean reads were aligned to the reference genome (hg38) sequencing using STAR 2.4.1 (24), and the gene expression levels (GRCh38) were quantified with the HTSeq package (25). The edgeR package (26) was used to select differentially expressed genes from sequencing count data.

RNA interference experiments. In this study, we used two RNA interference methods to knock down the CRMP4 gene, one for transient siRNA and the other for stable shRNA method. Small interfering RNA (siRNA) duplexes of CRMP4 were purchased from Bioneer (Daejeon, Korea). The specific target sequences of CRMP4 siRNA (\#2, Fig. S1A) were sense 5'-GUGGAA GGAUUGUAGUCAUdTdT-3' and antisense 5'-AUGACU ACAAUCCUUCCACdTdT-3'. siRNA duplexes were transfected into cells (50 nM for RKO, $200 \mathrm{nM}$ for SW620, SW480, Caco2, and KM12C) using Lipofectamine RNAiMAX reagent (Invitrogen; Thermo Fisher Scientific, Inc.). The short hairpin RNA (shRNA) targeting CRMP4 was obtained from Origene (TL313373V). The shRNA expression vector was transfected into the lentiviral packaging Lenti-X 293T cell line (Takara Bio USA). The culture supernatant containing virus particles was harvested $48 \mathrm{~h}$ post-transfection. For the stable transduction of the lentivirus, cells at $60-70 \%$ confluence were grown in 6-well 
plates. After $48 \mathrm{~h}, 1 \mu \mathrm{g} / \mathrm{ml}$ puromycin (Clontech Laboratories, Inc.) was added, and finally, CRMP4-knockdown RKO (\#1 clone) and SW620 (\#4 clone) cells were selected for further study (Fig. S1B).

Western blot analysis. Cells were lysed in radioimmunoprecipitation assay (RIPA) lysis buffer $[50 \mathrm{mM}$ Tris- $\mathrm{HCl}$ (pH 7.4), $150 \mathrm{mM} \mathrm{NaCl}, 1 \% \mathrm{NP} 40,0.25 \%$ sodium deoxycholate, $1 \mathrm{mM}$ PMSF, protease inhibitor mixture (Sigma-Aldrich; Merck KGaA), and $1 \mathrm{mM}$ sodium orthovanadate]. Proteins were separated using sodium dodecyl sulfate-polyacrylamide gel electrophoresis (SDS-PAGE), transferred to a polyvinylidene fluoride membrane, and blocked with 5\% skim milk/PBS-T buffer for $1 \mathrm{~h}$. Subsequently, the membrane was incubated with the following primary antibodies: $\beta$-actin, CRMP4, cytochrome $c$ (Santa Cruz Biotechnology, Inc.), and cleaved-PARP (cleaved-polyADP-ribose polymerase) (Cell Signaling Technologies, Inc.). The bound antibodies were visualized with a horseradish peroxidase-conjugated secondary antibody using enhanced chemiluminescence (Clarity Western ECL; Bio-Rad Laboratories, Inc.) and the Ez-Capture MG system (Atto Corp.).

Flow cytometry for the measurement of MMP, intracellular $\mathrm{Ca}^{2+}$ levels, and apoptosis assay. The fluorescent probe Fluo 3-AM was used for the assessment of intracellular levels of $\mathrm{Ca}^{2+}$ and the lipophilic cationic dye 3,3'-dihexyloxacarbocyanine iodide [DiOC6(3)] was used for measuring disruption of the MMP $(\Delta \psi \mathrm{m})$. Briefly, cells were exposed to a 5-Gy radiation dose and incubated for $72 \mathrm{~h}$, then stained with $1 \mu \mathrm{M}$ DiOC6(3) at $37^{\circ} \mathrm{C}$ for $15 \mathrm{~min}$ in the dark, and analyzed using FACSverse flow cytometry (BD Biosciences). For apoptosis analysis, cells were harvested and centrifuged at $800 \mathrm{rpm}$ for $3 \mathrm{~min}$ following radiation treatment $(48 \mathrm{~h})$. Cells were carefully resuspended, and hen Annexin-V (5 $\mu \mathrm{l})$ and propidium iodide (PI) (5 $\mu \mathrm{l}$ ) (BD Biosciences) were added, and the cells were incubated at $37^{\circ} \mathrm{C}$ for $15 \mathrm{~min}$ in the dark. The stained cells were analyzed using FACSverse flow cytometry (BD Biosciences) and the Flowjo software v7.6.1 (FlowJo LLC). At least 10,000 cells per sample were analyzed, and duplicate analyses were performed at each time point.

Clonogenic assay. Cells were seeded into 60-mm dish plates at densities of $1,2,5,8$, and $10 \times 10^{3}$ cells/plate. After $24 \mathrm{~h}$, cells were treated with the indicated ionizing radiation dose. After 14 days, the colonies were subsequently fixed, stained with $0.1 \%$ crystal violet in $20 \%$ ethanol, and counted. Alternatively, cells were stained with crystal violet; after a wash step, the dye was solubilized, and absorbance was measured at $590 \mathrm{~nm}$ using a microplate reader (Molecular Devices, LLC).

Cell cycle analysis. Irradiated cells were trypsinized, washed in ice-cold PBS, and fixed with $70 \%$ ethanol on ice. Fixed cells were stained with PI (BD Biosciences) containing RNase $(0.1 \mathrm{mg} / \mathrm{ml})$ for $15 \mathrm{~min}$ at $37^{\circ} \mathrm{C}$, and cell population analysis was performed using FACSCalibur flow cytometry.

Measurement of cytochrome c release. The cytochrome $c$ releasing apoptosis assay kit (Abcam; ab65311) was used for detecting cytochrome $c$ translocation from mitochondria into the cytosol. After irradiated or A23187-treated cells were lysed in a cytosolic extraction buffer and homogenized, the supernatant cytosolic fraction was separated by centrifugation, and the pellet was resuspended in a mitochondrial extraction buffer, according to the manufacturer's instructions. Separated cytosolic and mitochondrial fractions were immunoblotted for the measurement of cytochrome $c$ release.

Cell viability assay. Cell viability was assessed using the water-soluble tetrazolium salt (WST)-1 assay (Roche Diagnostics) according to the manufacturer's instructions. Briefly, $10 \mu \mathrm{l}$ WST-1 reagent was added to each well of a 96-well plate $\left(1 \times 10^{4}\right.$ cells/well). After incubation for $1 \mathrm{~h}$, the conversion of WST-1 reagent into chromogenic formazan was evaluated using a microplate reader.

Statistical analysis. All experiments were performed in triplicate and data are expressed as the means \pm standard deviation. Differences in cell apoptosis, survival, and MMP depolarization between control and CRMP4-deficiency cells were analyzed using a paired Student's t-test. Differences in cell survival among different cell groups (parent, IR-resistant, CRMP4-shRNA) were analyzed using one-way ANOVA with Tukey's post hoc test. Data were analyzed using GraphPad Prism (GraphPad Software Inc.). P<0.05 was considered statistically significant.

\section{Results}

Radiation-resistant cells exhibit CRMP4 downregulation and increased survival rate. To identify genes associated with radiation-induced cell death, radiation-resistant IR-SW620, IR-RKO, IR-SW480, and IR-HT-29 cell lines were established by repeated exposure to ionizing radiation over several weeks for a total exposure of $120 \mathrm{~Gy}(21,22)$. From the RNA sequencing analysis, a total of 25,207 genes were identified. Among them, 70 genes were upregulated ( $>1.5$-fold), while 45 were downregulated $(<0.5$-fold). These 115 genes were confirmed using RT-PCR analysis. Finally, the upregulated genes (CXCR4, RAC2, HBE1 (21), PTGDS, and LCN2) and downregulated genes (SMO, RGS10, PRTFDC1, and CRMP4) were identified as candidate genes associated with radiation resistance (Fig. 1A). To verify CRMP4 downregulation at the protein level, several colon cancer and IR-resistant cell lines were analyzed by western blotting (Fig. 1B). CRMP4 was differentially expressed in those; however, radiation-resistant IR-SW480, IR-SW620, and IR-RKO cells displayed apparent decreased CRMP4 expression compared to that of their parental cells. When SW620 and RKO cells showing high CRMP4 expression were compared with IR-SW620 and IR-RKO cells in regards to cell survival, IR-resistant cells exhibited better survival in the 5 Gy-irradiated clonogenic assay (Fig. 1C). The degree of apoptosis under exposure to $5 \mathrm{~Gy}$ of radiation, as analyzed by Annexin-V and PI, was significantly decreased by about half in IR-SW620 and IR-RKO cells compared to their parental cells (Fig. 1D). To investigate the effect of radiation on cell cycle distribution in IR-resistant cells and parental cells, cells were exposed to 0,2 , and 4 Gy of radiation. After $24 \mathrm{~h}$, cells were analyzed by flow cytometry using PI, and it revealed that radiation-mediated $\mathrm{G} 2 \mathrm{M}$ accumulation was reduced in both 
A

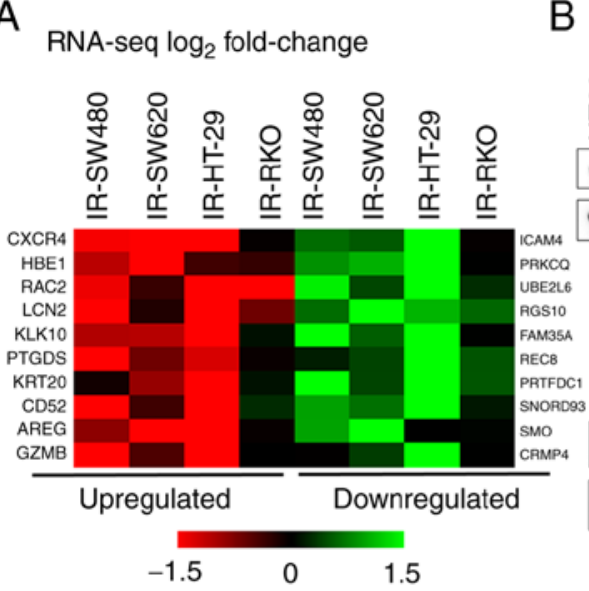

D

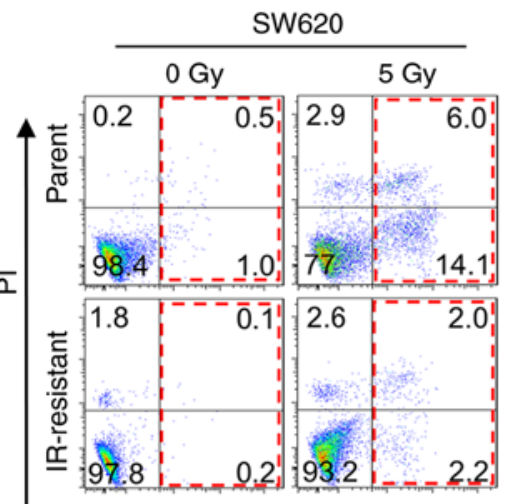

B
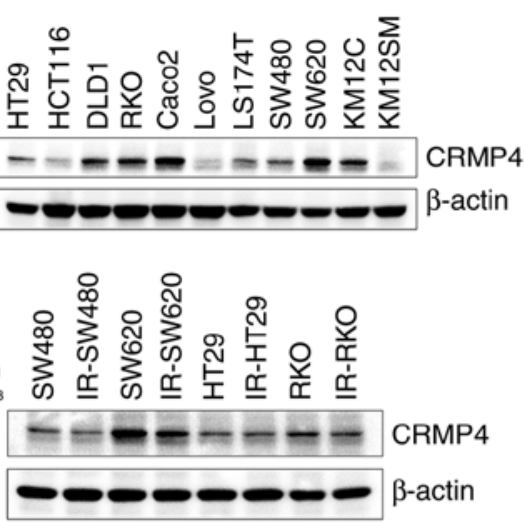

C
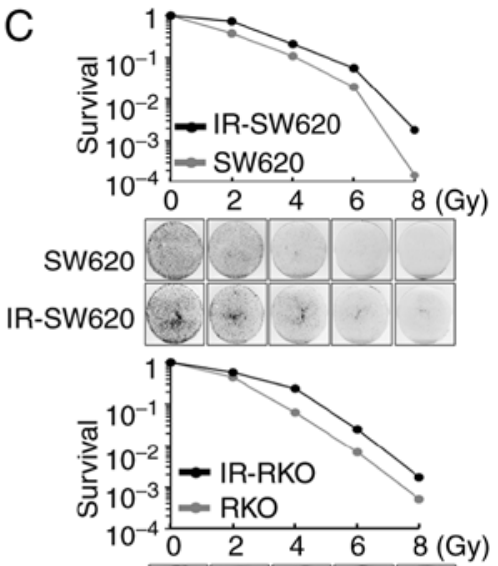

RKO

IR-RKO
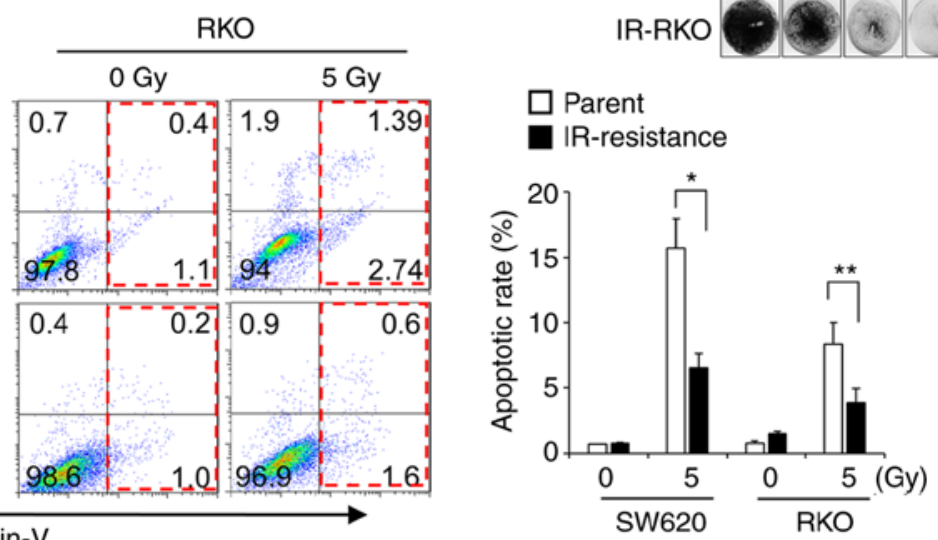

E

Annexin-V
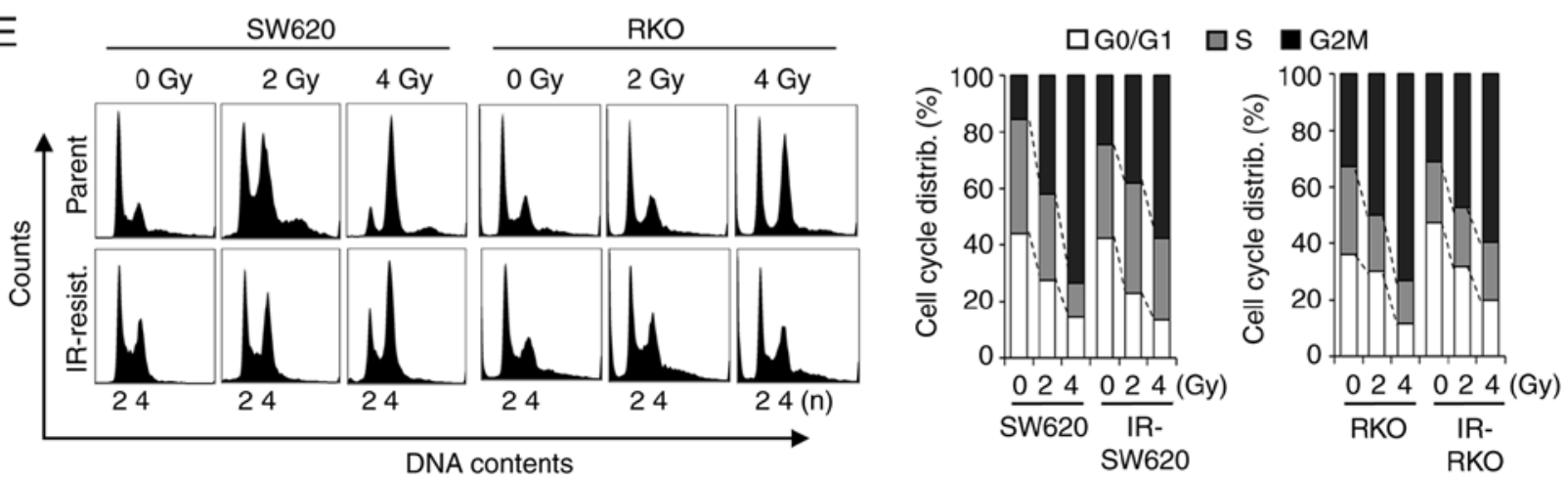

Figure 1. The ionizing radiation-resistant (IR) cell lines show CRMP4 downregulation and increased survival rate. (A) Heatmap from RNA sequencing results. Twenty representative genes are shown. CRMP4 was identified as a downregulated gene. (B) CRMP4 downregulation in IR-resistant cells. Several colon cancer cell lines were lysed and analyzed by western blotting. IR-cells were established by repeating radiation exposure as described in the Materials and methods. (C) Cells were irradiated to the indicated doses of radiation and allowed to grow for 2 weeks, and cells were stained with crystal violet and scored for the colony-forming capacity of irradiated cells. (D) Apoptosis inhibition in IR-resistant cells. Cells were treated with 5 Gy of radiation, and after $48 \mathrm{~h}$, cells were stained with Annexin-V and propidium iodide (PI) followed by flow cytometry analysis. Representative scatter plot and quantitative apoptotic rate (\%) are shown. Apoptotic cells (Annexin- $\mathrm{V}^{+} / \mathrm{PI}$, Annexin $-\mathrm{V}^{+} / \mathrm{PI}^{+}$) are indicated by red dotted rectangles. Student's t-test was performed. ${ }^{*} \mathrm{P}<0.05,{ }^{* *} \mathrm{P}<0.01$. (E) Reduced G2M phase accumulation in IR-resistant cells. Cells were treated with the indicated doses of radiation, and after $24 \mathrm{~h}$ the cell cycle was analyzed by flow cytometry using PI. The histogram (2n/4n DNA content) is shown on the left and their quantitative cell cycle distribution is shown on the right. CRMP4, collapsin response mediator protein 4.

IR-SW620 and IR-RKO cells compared to their parent cells (Fig. 1E).

siRNA-mediated CRMP4 knockdown causes radiation resistance. Loss-of-function experiments using siRNAs were performed on colon cancer cells to determine whether CRMP4 reduction is involved in radiation resistance. When RKO and SW620 cells were treated with CRMP4-siRNA, there was a 5-fold reduction in CRMP4 protein expression (Fig. S1A), although the siRNA amount was treated differently based on transfection efficiency for each cell line types. To verify the results from CRMP4-siRNA transfected SW620 and RKO cells, colon cancer cell lines SW480, Caco2 and KM12C, all of which express CRMP4, were selected and transfected with CRMP4-siRNA. The clonogenic assays revealed that CRMP4 reduction was associated with resistance to radiation in these 
A
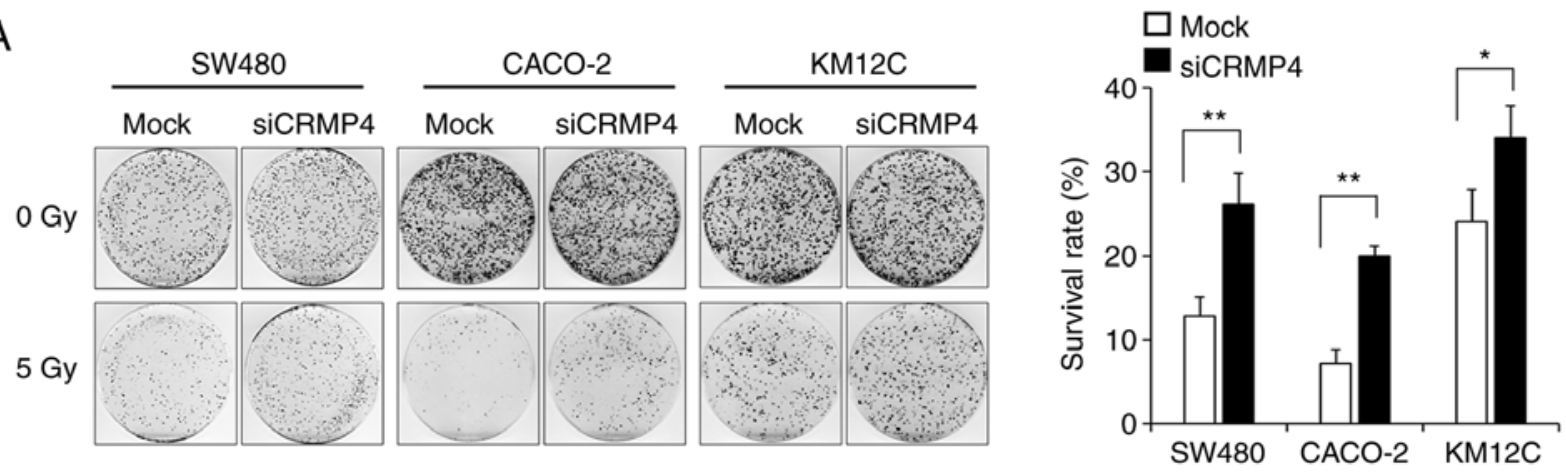

B
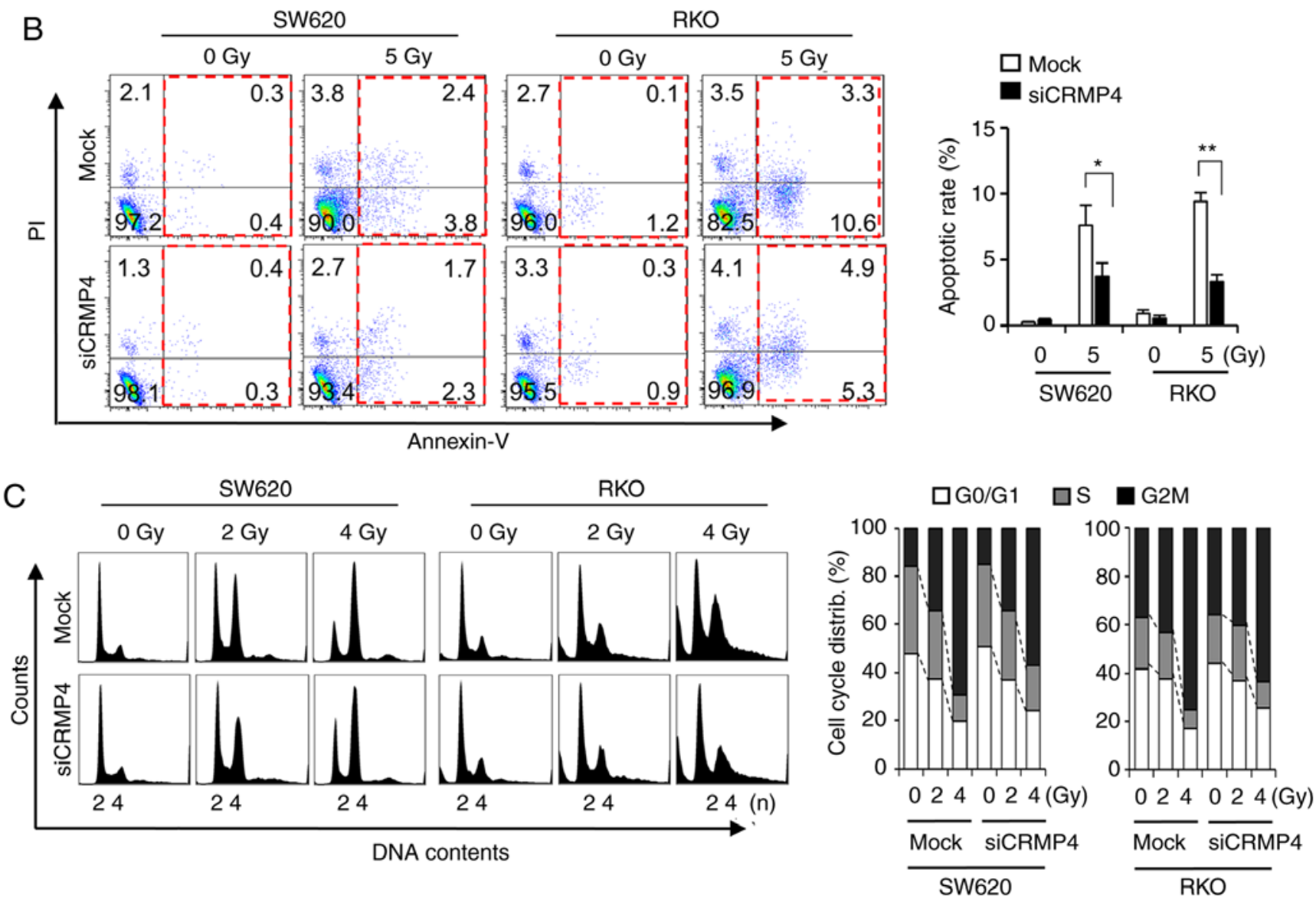

Figure 2. CRMP4-deficiency enhances resistance to radiation. (A) Increased radioresistance in siCRMP4 cells. After cells were transfected with control siRNA (Mock) or CRMP4 siRNA, cells were treated with radiation $(5 \mathrm{~Gy})$ and analyzed by clonogenic assay. Representative images are shown on the left, and a quantitative graph is shown on the right. Student's t-test was performed. ${ }^{*} \mathrm{P}<0.05,{ }^{* *} \mathrm{P}<0.01$. (B) Inhibition of apoptosis in siCRMP4 cells. Cells were treated with $5 \mathrm{~Gy}$ of radiation for $48 \mathrm{~h}$, stained with Annexin-V and propidium iodide (PI), and the percentages of apoptotic cells were measured by flow cytometry. Representative scatter plot and quantitative apoptotic rate (\%) are shown. Apoptotic cells (Annexin- $\mathrm{V}^{+} / \mathrm{PI}^{-}$, Annexin- $\left.\mathrm{V}^{+} / \mathrm{PI}^{+}\right)$are indicated by red dotted rectangles. Student's t-test was performed. ${ }^{*} \mathrm{P}<0.05,{ }^{* *} \mathrm{P}<0.01$. (C) Reduced G2M phase accumulation in siCRMP4 cells. Cells were treated with the indicated doses of radiation, and after $24 \mathrm{~h}$ the cell cycle was analyzed by flow cytometry using PI. The histogram ( $2 \mathrm{n} / 4 \mathrm{n}$ DNA content) is shown on the left and their quantitative cell-cycle distribution is shown on the right. CRMP4, collapsin response mediator protein 4.

cells (Fig. 2A). To ascertain whether increased clonogenic survival by CRMP4 knockdown was associated with reduced apoptosis, Annexin V and PI staining was used to examine the degree of apoptosis induced by radiation in CRMP4knockdown and mock cells (Fig. 2B). The number of apoptotic cells following radiation treatment in the CRMP4-knockdown cells was significantly decreased by half compared to that found in the mock cells transfected with nonspecific control siRNA. In cell cycle analysis, radiation-exposed CRMP4-knockdown cells displayed decreased G2/M accumulation compared to the control cells (Fig. 2C). These results suggest that CRMP4 may be associated with the development of radiation resistance in colon cancer cells.

CRMP4-deficiency attenuates radiation-induced cytochrome c release from mitochondria. Irradiation has been shown to induce various cellular and molecular damage outcomes, including apoptosis, in which cytochrome $c$ release from mitochondria constitutes a critical event (27). The amount of cytochrome $c$ released from the mitochondria of irradiated 
A

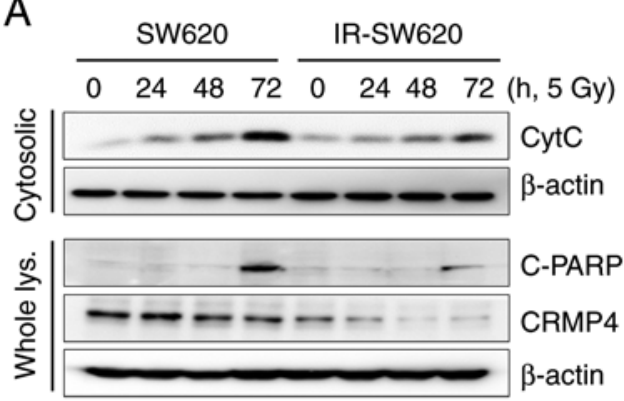

B

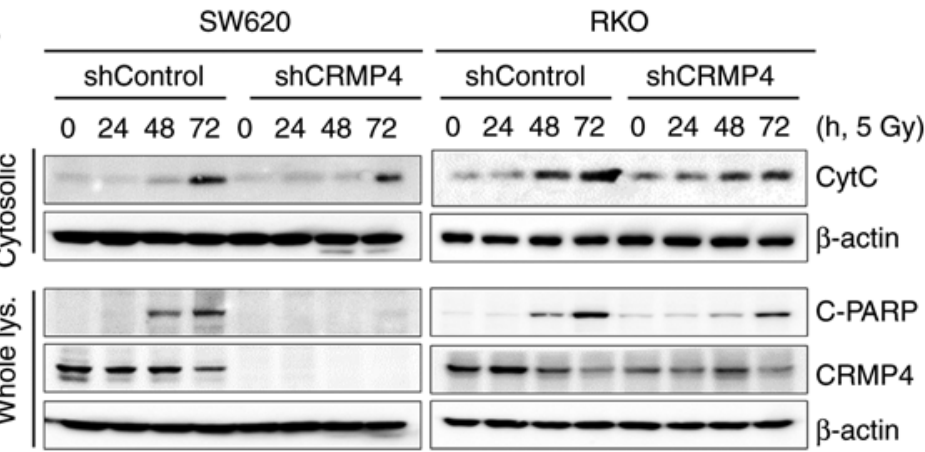

C

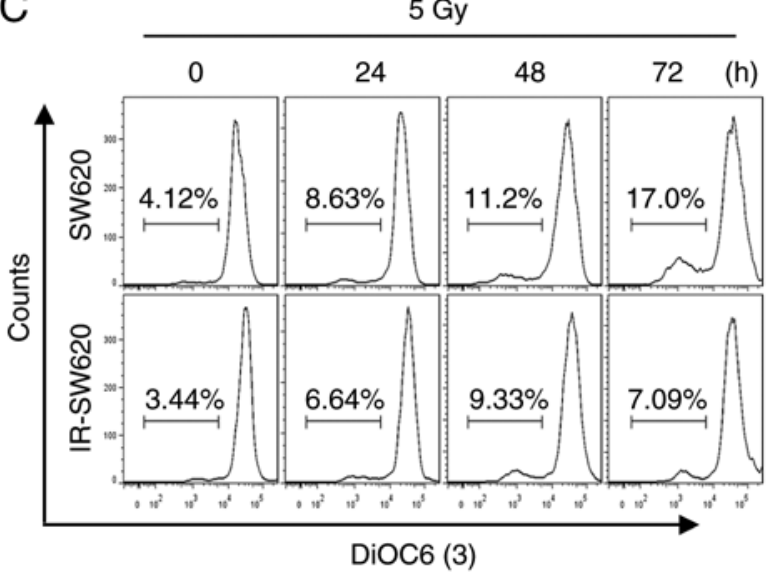

$\square$ SW620

IR-SW620

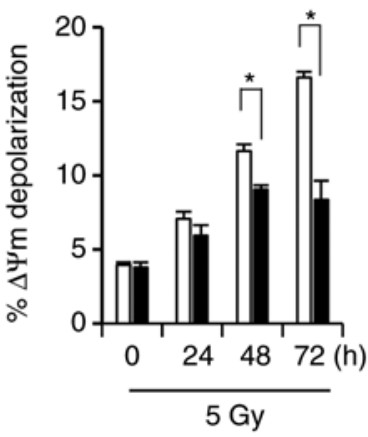

D $\quad$ Q 0 Gy

SW620

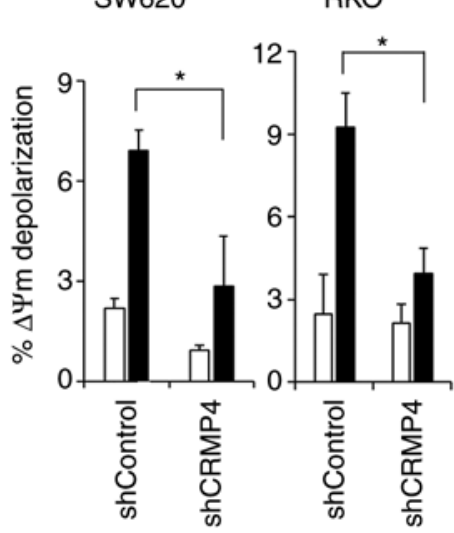

Figure 3. CRMP4-deficiency inhibits mitochondrial membrane depolarization under radiation exposure. (A) Inhibition of cytochrome $c$ (CytC) release and PARP cleavage (C-PARP) in IR-resistant cells. After cells were exposed to $5 \mathrm{~Gy}$ of radiation for 0-72 h, cytosolic fractions were isolated and western blotting was conducted. (B) Inhibition of cytochrome $c$ release and PARP cleavage in shCRMP4 cells. After cells were exposed to 5 Gy of radiation, cytosolic fractions were isolated and western blotting was conducted. (C) MMP depolarization was significantly increased in parental cells but not in ionizing radiation (IR)-resistant cells. After cells were exposed to $5 \mathrm{~Gy}$ of radiation, cells were stained with DIOC6(3) (3,3'-dihexyloxacarbocyanine iodide) fluorescent dye and analyzed by flow cytometry. The quantitative graph is shown on the right. Student's t-test was performed. * $<<0.05$. (D) After cells were exposed to 5 Gy of radiation for $72 \mathrm{~h}$, cells were analyzed by flow cytometry using DiOC6(3). MMP depolarization was strongly increased in shControl cells, but it was weakly increased in shCRMP4 cells. Student's t-test was performed. ${ }^{*} \mathrm{P}<0.05$. CRMP4, collapsin response mediator protein 4 ; MMP, mitochondrial membrane potential; PARP, polyADP-ribose polymerase.

cells was measured using a mitochondria/cytosol fractionation method. As shown in Fig. 3A, irradiated cells induced cytochrome $c$ release in a time-dependent manner. The maximum amount of cytochrome $c$ release was attained at $72 \mathrm{~h}$ of exposure to 5 Gy of radiation. However, decreased cytochrome $c$ release and PARP cleavage were observed in the CRMP4-deficiency IR-SW620 cells compared to the parental cells. To verify the role of CRMP4 in cancer cells as regards radiation resistance, CRMP4 expression was stably knocked down in SW620 and RKO cells through lentiviral-mediated shRNA infection (Fig. S1B). After CRMP4 knockdown was verified in both cell lines, cytochrome $c$ release was evaluated under radiation exposure. As expected, mitochondrial cytochrome $c$ release and PARP cleavage were decreased in CRMP4-knockdown SW620-shCRMP4 and RKO-shCRMP4 cells compared to the nonspecific control shRNA cells (Fig. 3B). It has been known that the release of cytochrome $c$ from mitochondria during apoptosis is associated with low MMP $(\Delta \Psi \mathrm{m})$. The lipophilic cationic dye 3DiOC6(3) was used to monitor MMP and determine whether CRMP4 reduction is associated with MMP loss. Radiation treatment gradually caused the SW620 cells to lose MMP in a time-dependent manner, whereas IR-SW620 cells showed a weak depolarization of MMP (Fig. 3C). Similarly, CRMP4-knockdown cells also exhibited insignificant depolarization of MMP, but shControl cells showed a 2.3-fold increase in depolarization (Fig. 3D). These results indicate that CRMP4 deficiency may diminish radiation-induced MMP depolarization and cytochrome $c$ release.

CRMP4 deficiency attenuates $\mathrm{Ca}^{2+}$-mediated cell death pathway. Consequent to its role as an incredibly versatile signaling ion, uncontrolled cytosolic $\mathrm{Ca}^{2+}$ influx induces mitochondrial dysfunction and cell death pathways $(3,18)$. To determine whether CRPM4 could modulate intracellular $\mathrm{Ca}^{2+}$ influx, $\mathrm{Ca}^{2+}$ concentration was measured by flow cytometry using a cell-permeable fluorescent $\mathrm{Ca}^{2+}$ indicator, Fluo 3-AM. As shown in Fig. 4A, radiation exposure strongly induced intracellular $\mathrm{Ca}^{2+}$ influx regardless of CRMP4 expression (Fig. 4A). When $\mathrm{Ca}^{2+}$ levels were analyzed in cells expressing the siRNA- or shRNA-CRMP4 as a preliminary experiment (data not shown), the significant difference in $\mathrm{Ca}^{2+}$ concentration according to CRMP4 expression could not be determined. Under radiation exposure, intracellular $\mathrm{Ca}^{2+}$ concentration was strongly elevated in all radiation-treated cells irrespective of 
A

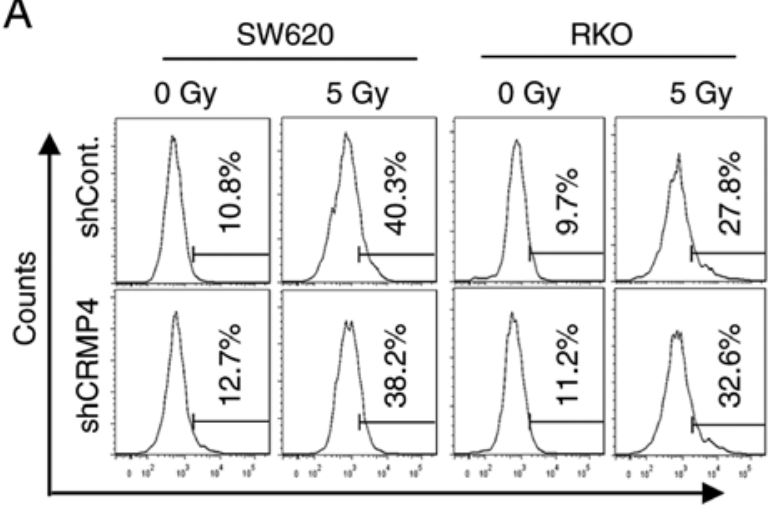

FITC (Fluo 3-AM)
SW620

$\square 0$ Gy

5 Gy

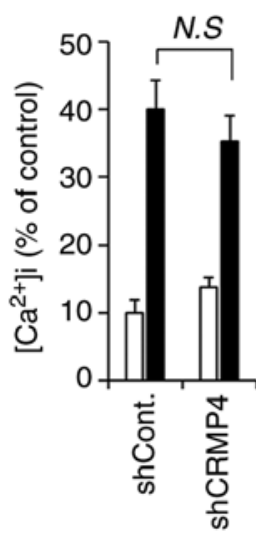

RKO
B

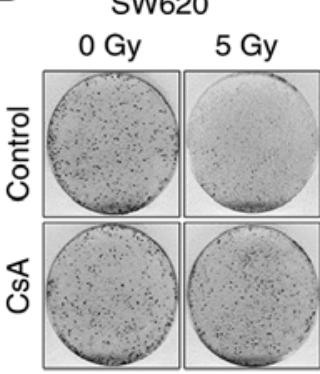

C

\section{SW620 \\ 口IR-SW620 \\ 口ShCRMP4}

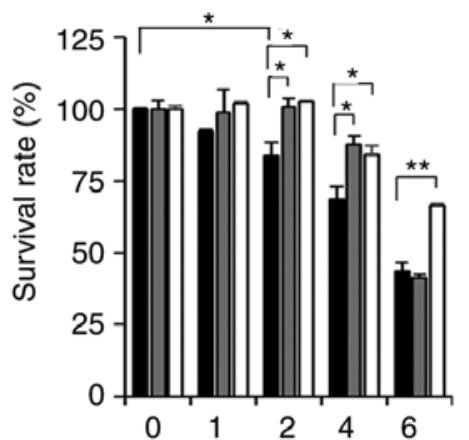

RKO

口IR-RKO

口ShCRMP4

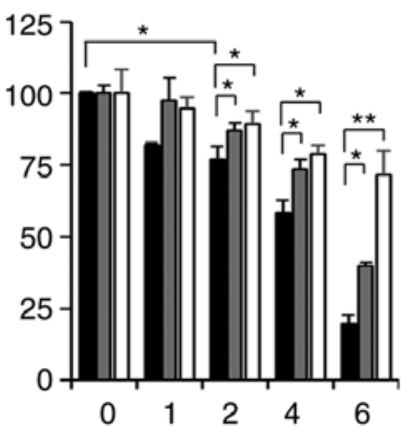

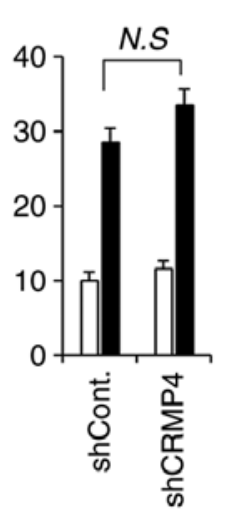

范

$\square 0$ Gy

5 Gy
D

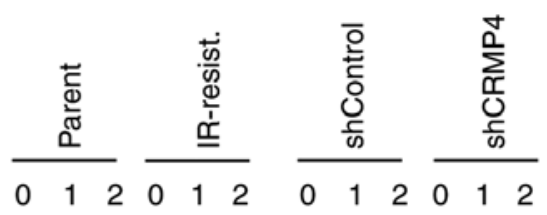

(A23187)

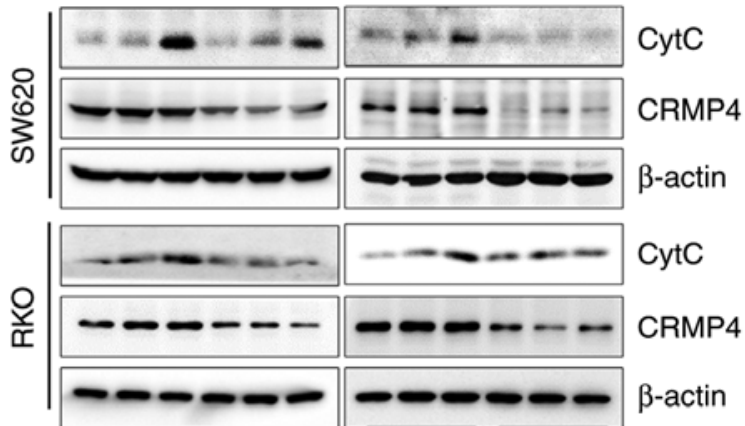

A23187 $(\mu \mathrm{M})$

E

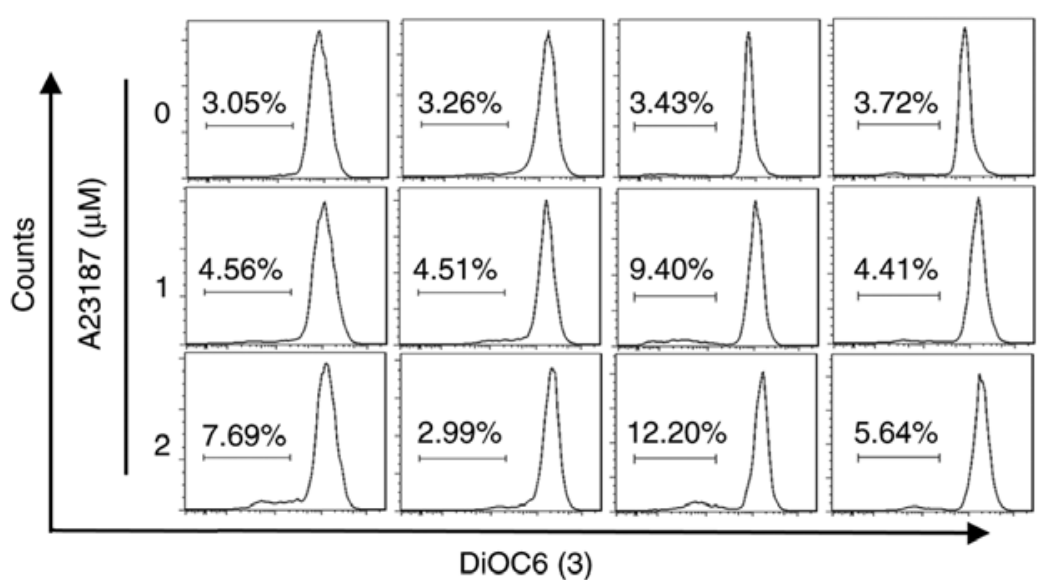

$\square$ shControl

shCRMP4
SW620 RKO

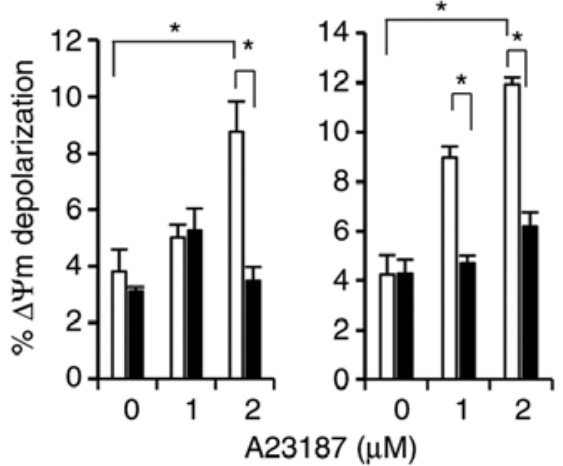

Figure 4. CRMP4-deficiency inhibits the $\mathrm{Ca}^{2+}$-mediated cell death pathway. (A) Intracellular $\mathrm{Ca}^{2+}$ level was not affected by CRMP4-deficiency. Cells were irradiated with $5 \mathrm{~Gy}$ of radiation for $72 \mathrm{~h}$, treated with Fluo-3 AM for $\mathrm{Ca}^{2+}$ detection, and analyzed by flow cytometry. Histograms of intracellular $\mathrm{Ca}^{2+}$ content are shown on the right. N.S, not significant. (B) Increased cell survival by cyclosporine A (CsA) in radiation-treated cells. Cells were treated with or without CsA $(5 \mu \mathrm{M})$ for $1 \mathrm{~h}$ and exposed to $5 \mathrm{~Gy}$ of radiation, and after 14 days, cells were stained with $0.1 \%$ crystal violet. (C) CRMP4-deficiency inhibited A23187-mediated cell death. Several cells were treated with the $\mathrm{Ca}^{2+}$ ionophore A23187 for $24 \mathrm{~h}$, and their proliferation was measured by a plate reader using the WST-1 reagent. The survival rate is expressed as the \% of control cells. Student's t-test was performed. ${ }^{*} \mathrm{P}<0.05,{ }^{* * *} \mathrm{P}<0.01$. (D) Cytochrome $c(\mathrm{CytC})$ release inhibition in CRMP4-downregulated cells. After cells were treated with A23187 (0-2 $\mu \mathrm{M})$ for $12 \mathrm{~h}$, the cytosolic fractions were isolated and western blotting was conducted. CRMP4-deficient ionizing radiation (IR)-resistant and shCRMP4 cells showed a decreased cytochrome $c$ release. (E) MMP depolarization was increased in shControl cells but not in shCRMP4 cells. After cells were treated with A23187 for $24 \mathrm{~h}$, cells were stained with DIOC6(3) and analyzed by flow cytometry. The quantitative graph is shown on the right. Student's t-test was performed. "P $<0.05$. CRMP4, collapsin response mediator protein 4; MMP, mitochondrial membrane potential. 

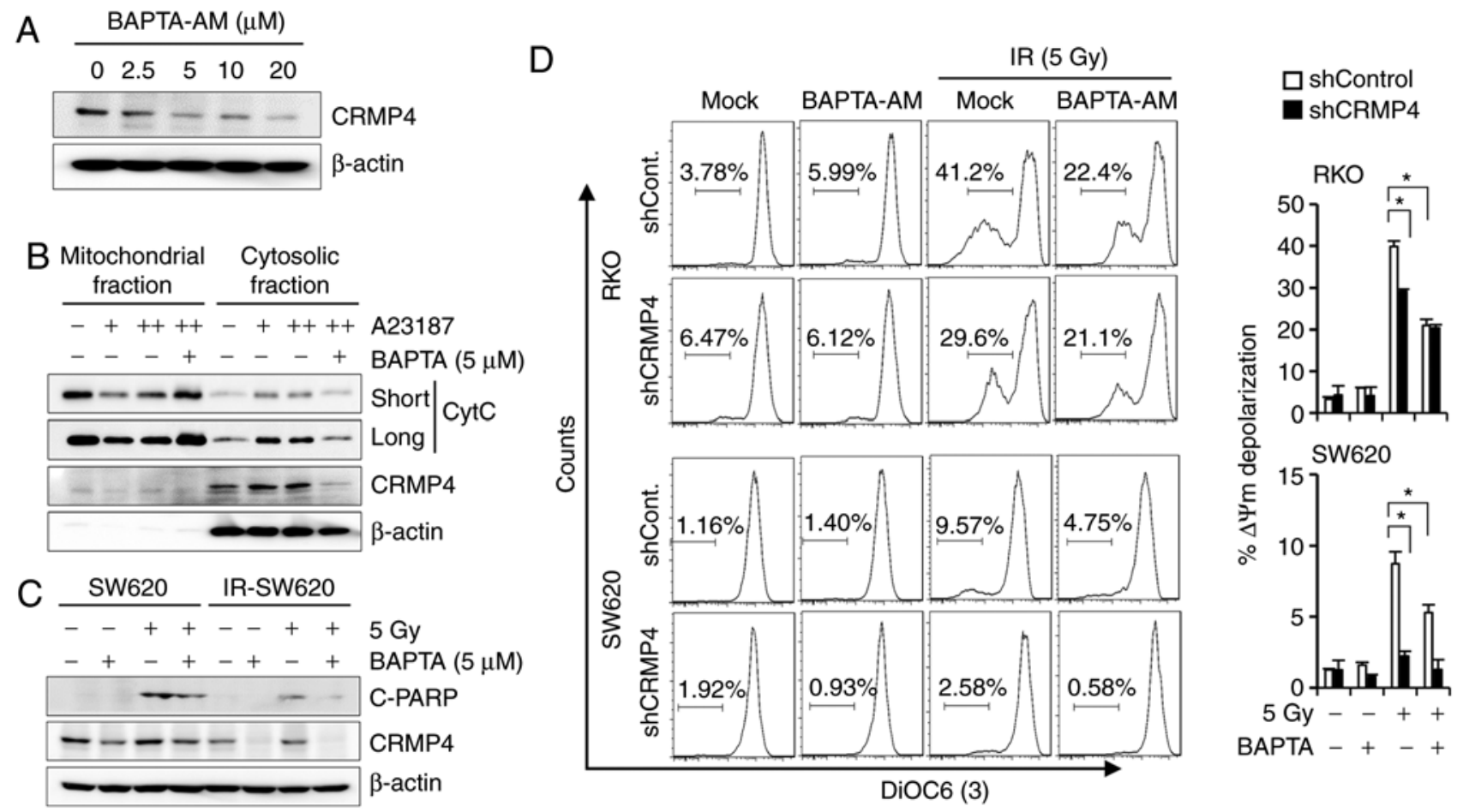

Figure 5. The $\mathrm{Ca}^{2+}$ chelator, BAPTA-AM, downregulates CRMP4 and inhibits MMP depolarization. (A) CRMP4 downregulation by BAPTA-AM treatment. SW620 cells were treated with BAPTA-AM $(0-20 \mu \mathrm{M})$ for $24 \mathrm{~h}$, and western blotting was conducted. (B) A23187-mediated cytochrome $c$ (CytC) release was inhibited by BAPTA-AM. SW620 cells were treated with A23187 $(+, 1 \mu \mathrm{M} ;++, 2 \mu \mathrm{M})$ in the absence or presence of BAPTA-AM $(5 \mu \mathrm{M})$ for $12 \mathrm{~h}$, and mitochondrial and cytosolic fractions were isolated for western blotting. (C) Radiation-mediated PARP cleavage (C-PARP) was blocked by BAPTA-AM. Cells were treated with BAPTA-AM $(5 \mu \mathrm{M})$ and/or radiation ( $5 \mathrm{~Gy})$, and after $72 \mathrm{~h}$, cell lysates were analyzed by western blotting. (D) Radiation-mediated MMP depolarization was inhibited by BAPTA-AM. Cells were treated with BAPTA-AM $(5 \mu \mathrm{M})$ and/or radiation (5 Gy), and after $72 \mathrm{~h}$, cells were stained with DiOC6(3) for flow cytometry. The quantitative graph is shown on the right. Student's t-test was performed. "P $<0.05$. CRMP4, collapsin response mediator protein 4; MMP, mitochondrial membrane potential.

CRMP4 expression (Fig. 4A), indicating that CRMP4 is not likely involved in intracellular $\mathrm{Ca}^{2+}$ influx regulation. Because improper $\mathrm{Ca}^{2+}$ influx into mitochondria causes MMP depolarization, we verified the consequent radiation-induced cell death using the clonogenic assay (Fig. 4B). When cells were treated with cyclosporin A (CsA), known to inhibit $\mathrm{Ca}^{2+}$-dependent mitochondrial permeability transition (MPT) pores, cells exhibited strong radiation-resistant survival compared to CsA-untreated control cells, indicating that $\mathrm{Ca}^{2+}$ is critical to radiation-induced cell death. To examine whether CRMP4 is required for $\mathrm{Ca}^{2+}$-mediated apoptosis or MMP depolarization, cells were treated with the $\mathrm{Ca}^{2+}$ ionophore $\mathrm{A} 23187$ to increase intracellular $\mathrm{Ca}^{2+}$ levels. As shown in Fig. 4C, IR-resistant and shCRMP4 cells exhibited dose-dependent improved survival compared to control parent cells upon A23187 treatment. Western blotting analysis further revealed that cytochrome $c$ release from mitochondria was obviously reduced in the IR-resistant and shCRMP4 cells compared to the control cells under A23187 treatment (Fig. 4D). Consistent with this, when A23187-treated cells were analyzed by flow cytometry using DiOC6(3), MMP depolarization was significantly increased in shControl cells but not in shCRMP cells (Fig. 4E), indicating that CRMP4 may play a role in $\mathrm{Ca}^{2+}$-mediated MMP depolarization followed by mitochondrial cytochrome $c$ release and apoptosis.

$\mathrm{Ca}^{2+}$ chelator BAPTA-AM downregulates CRMP4 and enhances radioresistance. Previously, we found that
CsA-mediated MPT inhibition caused the downregulation of CRMP4. To examine whether CRMP4 expression is affected by intracellular $\mathrm{Ca}^{2+}$ levels, cells were treated with the cell-permeant intracellular $\mathrm{Ca}^{2+}$ chelator, BAPTA-AM, and cell lysates were analyzed with western blotting. Interestingly, CRMP4 was downregulated by BAPTA-AM treatment in a dose-dependent manner (Fig. 5A). Although we could not determine whether CRMP4 was proteolyzed or degraded in this condition, CRMP4 expression may be regulated by the $\mathrm{Ca}^{2+}$-related pathway. The buffering of intracellular $\mathrm{Ca}^{2+}$ concentration by BAPTA-AM $(5 \mu \mathrm{M})$ also obviously reduced A23187-induced cytochrome $c$ release in SW620 cells (Fig. 5B). Western blotting results showed that cleaved-PARP was augmented following radiation exposure, but IR-SW620 cells revealed a strong inhibition of PARP cleavage under radiation exposure following BAPTA-AM treatment (Fig. 5C). Consistently, when cells were analyzed with flow cytometry using DiOC6, BAPTA-AM attenuated radiation-induced MMP depolarization in both shCRMP4 and shControl cells (Fig. 5D). These data suggest that low BAPTA-AM $(<5 \mu \mathrm{M})$ could alleviate A23187- and radiation-induced MMP depolarization and cytochrome $c$ release.

Cell death is increased in CRMP4-deficient cells treated with high BAPTA-AM. Several studies have demonstrated the extensive use of BAPTA-AM for buffering $\mathrm{Ca}^{2+}$; however, high concentrations of BAPTA-AM have been found to deplete intracellular $\mathrm{Ca}^{2+}$ stores $(10,28)$. To ascertain whether the 

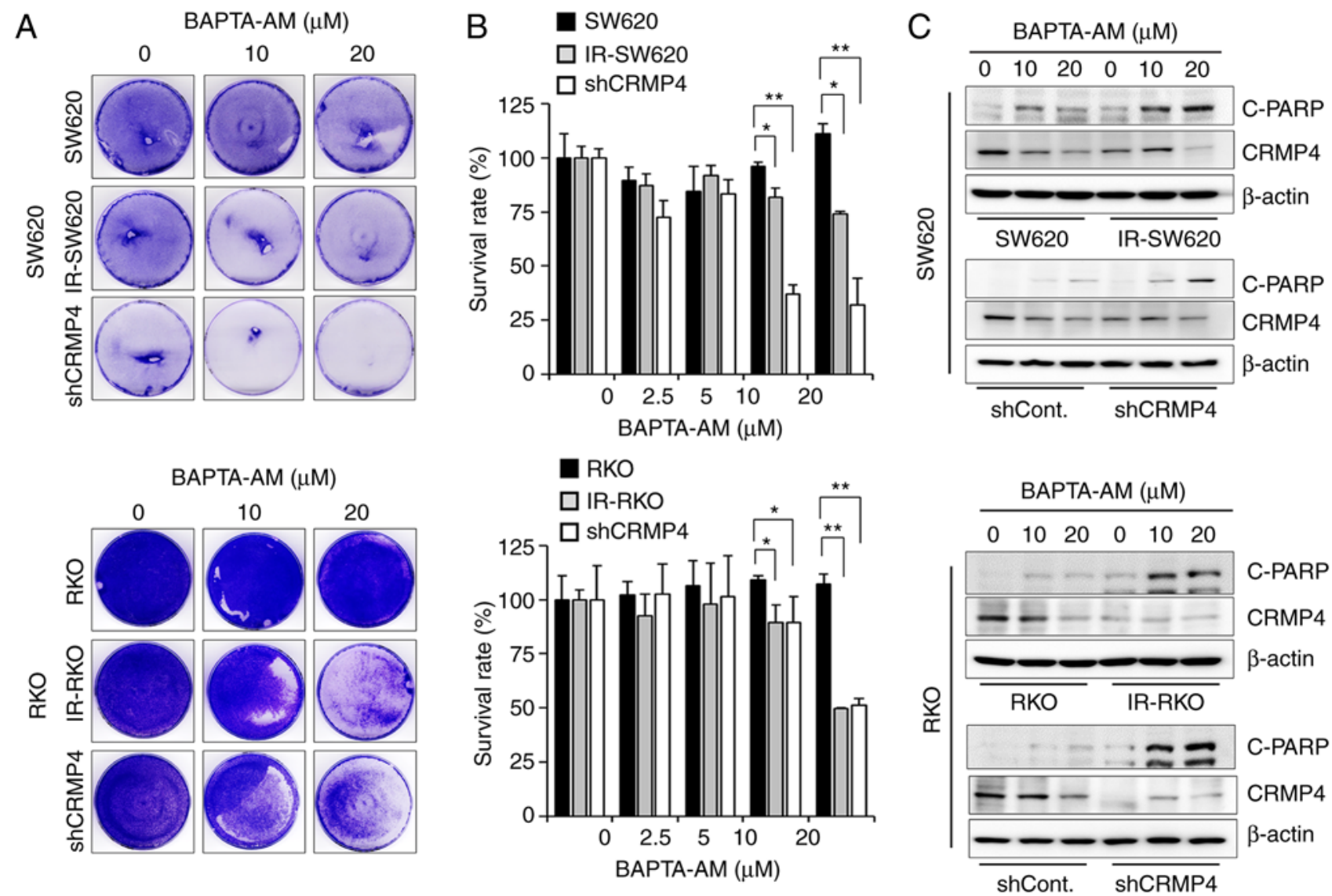

Figure 6. High-dose BAPTA-AM enhances cell death in CRMP4-deficient cells. (A) Cells were treated with the indicated doses of BAPTA-AM for $72 \mathrm{~h}$, and cells were stained with crystal violet. Representative images are shown. (B) Cell survival inhibition in CRMP4-deficient cells with BAPTA-AM. After cells were treated with BAPTA-AM $(>10 \mu \mathrm{M})$ for $48 \mathrm{~h}$, cells were incubated with the WST-1 reagent, and their absorbances at $\mathrm{OD}_{450}$ were read using a plate reader. One-way ANOVA with Tukey's post hoc test between control, ionizing radiation (IR)-resistant, and shCRMP4 groups were performed. ${ }^{*} \mathrm{P}<0.05,{ }^{* *} \mathrm{P}<0.01$. (C) Cleaved PARP (C-PARP) induction in CRMP4-deficient cells with BAPTA-AM. After cells were treated with BAPTA-AM for $48 \mathrm{~h}$, cell lysates were analyzed by western blotting. C-PARP was strongly increased in IR-resistant and shCRMP4 cells compared to control cells. CRMP4, collapsin response mediator protein 4; PARP, polyADP-ribose polymerase.

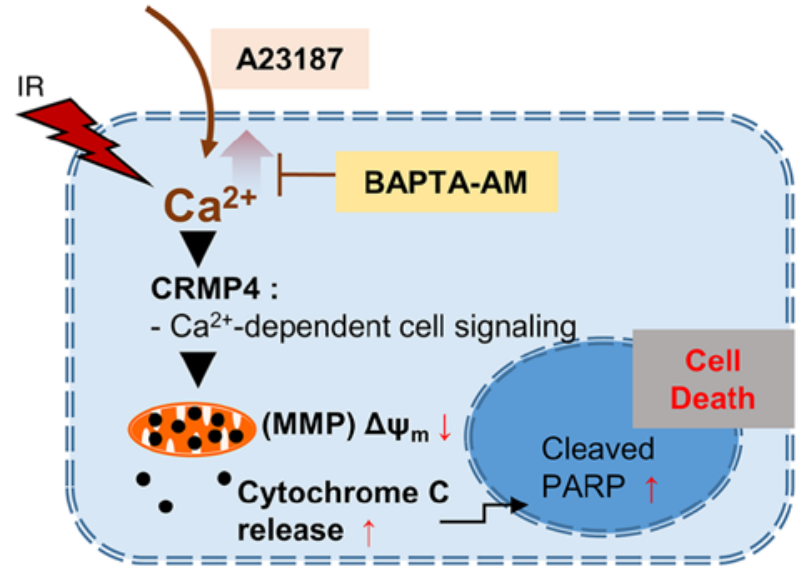

Figure 7. Radiation-mediated CRMP4 downregulation inhibits the mitochondrial membrane depolarization followed by apoptosis induction. Radiation- or $\mathrm{Ca}^{2+}$ ionophore A23187-mediated improper intracellular $\mathrm{Ca}^{2+}$ influx collapses the cellular $\mathrm{Ca}^{2+}$-mediated pathway followed by MMP depolarization. Apoptosis resulting from radiation or A23187 treatment is diminished by CRMP4-deficiency and low levels of the intracellular $\mathrm{Ca}^{2+}$ chelator, BAPTA-AM $(<5 \mu \mathrm{M})$. Conversly, significant cell death can be triggered by CRMP4-deficiency and a high dose of BAPTA-AM $(>10 \mu \mathrm{M})$ This suggests that CRMP4 plays an important role in the $\mathrm{Ca}^{2+}$-mediated cell death pathway. CRMP4, collapsin response mediator protein 4; MMP, mitochondrial membrane potential; PARP, polyADP-ribose polymerase; IR, ionizing radiation. apoptosis inhibition in CRMP4-deficient cells is changed under high BAPTA-AM levels ( $>10 \mu \mathrm{M})$, several CRMP-deficient cell lines were treated with 10-20 $\mu \mathrm{M}$ of BAPTA-AM, and surviving cells were stained with crystal violet dye (Fig. 6A). Furthermore, WST-1 assay was conducted for cell viability measurement (Fig. 6B). High BAPTA-AM-induced $\mathrm{Ca}^{2+}$ deficiency-mediated cell death in both IR-resistant and CRMP4-knockdown cells in a dose-dependent manner, but no significant effect was observed in the parental cells, indicating that $\mathrm{Ca}^{2+}$ deficiency-induced apoptosis may be associated with the CRMP4 expression level. In addition, there was an obvious dose-dependent cleaved-PARP elevation in both IR-resistant and shCRMP4 cells treated with BAPTA-AM (Fig. 6C). Parental and shControl cells showed a weak cleavage of PARP. Therefore, these results suggest that CRMP4 may be important for cell survival during cellular stress response due to BAPTA-AM-induced $\mathrm{Ca}^{2+}$ deficiency.

\section{Discussion}

Previously, $\gamma$-irradiation-resistant colon cancer cell lines were established, and novel candidate molecules implicated in radioresistance were identified using RNA sequencing analysis (21). Among the genes significantly downregulated in 
radioresistant cell lines than in their parental cells, collapsin response mediator protein 4 (CRMP4) was further examined in the present study concerning the association between tumor growth and radioresistance. It is known that CRMPs influence various intracellular signal transduction pathways, including VEGF, RhoA, GSK3 $\beta$, and Sema3A $(29,30)$; moreover, CRMP4 is involved in neurodevelopmental disorders such as schizophrenia, neurological disorders such as Alzheimer's disease (31), and various types of cancers such as breast, prostate, gastric, and hepatocellular carcinomas (11,32-35).

Until now, the relationship between CRMP4 and $\mathrm{Ca}^{2+}$ influx stress or $\mathrm{Ca}^{2+}$ homeostasis has not been defined. We assayed $5-G y$ radiation-mediated intracellular $\mathrm{Ca}^{2+}$ concentration in shControl- and shCRMP4-SW620 and -RKO cells (Fig. 4A). $\mathrm{Ca}^{2+}$ levels were increased highly in all radiation-treated cells, but no statistical significance between the $\mathrm{Ca}^{2+}$ levels of shControl and shCRMP4 cells was identified in both radiation-treated and -untreated cells. Similarly, the siRNA experiment did not show statistical significance between the $\mathrm{Ca}^{2+}$ levels of siControl and siCRMP4 cells (data not shown). As revealed by the data, under the radiation-untreated condition, survival, apoptosis, and cell cycle distribution were not significantly different between siControl and siCRMP4 cells. Therefore, it is not likely that CRMP4 regulates intracellular $\mathrm{Ca}^{2+}$ influx.

$\mathrm{Ca}^{2+}$ is a ubiquitous diffusible intracellular second messenger released inside cells upon ligand interaction with membrane receptors; it is especially associated with diverse cellular functions related to cell growth; however, it can induce apoptosis. A primary cause of $\mathrm{Ca}^{2+}$-induced mitochondrial damage is the nonspecific pore opening of the mitochondrial membrane leading to the activation of mitochondrial permeability transition (MPT), causing loss of mitochondrial membrane potential (MMP), rupture of the outer mitochondrial membrane, and leakage of intermembrane proteins, such as cytochrome $c$, to the cytoplasm (36-38). Therefore, the disruption of $\mathrm{Ca}^{2+}$ homeostasis in cells affects various signaling pathways, including those associated with proliferation and apoptosis $(15,28)$. It was recently reported that patients with Hodgkin's lymphoma who received a total dose of more than $30 \mathrm{~Gy}$ of radiation displayed significantly higher $\mathrm{Ca}^{2+}$ scores than other patients, putting them at a higher risk of coronary artery disease (39). Nonetheless, our understanding of the correlation between radiation exposure and $\mathrm{Ca}^{2+}$ homeostasis remains insufficient. Our data showed a considerable relationship between radiation-resistance and CRMP4 downregulation. When CRMP4-deficient cells such radiation-resistant and $C R M P 4$-shRNA-infected cells were treated with radiation or $\mathrm{Ca}^{2+}$ ionophore A23187, intracellular $\mathrm{Ca}^{2+}$ influx caused high $\mathrm{Ca}^{2+}$ concentrations regardless of CRMP4, but MMP depolarization followed by apoptosis was significantly inhibited according to CRMP4 deficiency (Figs. 3 and 4). Therefore, it can be inferred that CRMP4 plays an important role in the $\mathrm{Ca}^{2+}$-mediated cell death pathway in colon cancer cells (Fig. 7).

In addition, the cellular effects of BAPTA-AM, a cell-permeant intracellular $\mathrm{Ca}^{2+}$ chelator that acts as an intracellular $\mathrm{Ca}^{2+}$ buffer, were investigated. Interestingly, CRMP4 was obviously downregulated in BAPTA-AM-treated cells (Fig. 5), suggesting that CRMP4 expression may be regulated depending on the $\mathrm{Ca}^{2+}$-related process. Although it was not determined why CRMP4 was downregulated or whether CRMP4 protein was cleaved (or degraded) in a BAPTA-AM-treated or radiation-treated condition, it is clear that CRMP4 downregulation was strongly involved in the inhibition of $\mathrm{Ca}^{2+}$-mediated MMP depolarization. In addition, low BAPTA-AM $(<5 \mu \mathrm{M})$ treatment diminished A23187- or radiation-mediated apoptosis. However, under high BAPTA-AM (>10 $\mu \mathrm{M}$ ) conditions (Fig. 6), CRMP4-deficiency from IR-resistant or shCRMP4 cell lines caused increased cell death, suggesting that proper intracellular $\mathrm{Ca}^{2+}$ levels modulated by BAPTA-AM may be critical for cell survival and cell death. Therefore, there may be a close relationship between CRMP4 and $\mathrm{Ca}^{2+}$-mediated apoptosis pathway under radiation exposure (Fig. 7), although further study is needed. According to previous studies, several intracellular protein transport systems can be affected by the chelation of $\mathrm{Ca}^{2+}$ with BAPTA-AM (40), potentially including vesicle formation. It was therefore predicted herein that CRMP4 could be involved in $\mathrm{Ca}^{2+}$ signaling since CRMP4 activity would be essential for cell survival during intracellular $\mathrm{Ca}^{2+}$ deficiency.

Our results also indicated that CRMP4 expression levels were altered by several factors, including radiation exposure, CsA or BAPTA-AM treatment, implying that CRMP4 may be an adjustable target protein. It has been reported that CRMP4 expression levels are regulated by miRNAs. miR-130a upregulation has been reported to target the 3'UTR region of CRMP4 in gastric cancer cells and promote tumor progression via CRMP4 inhibition (41). Conversely, VEGF enhances CRMP4 expression levels in gastric cancer cells, which is inhibited by the MAPK inhibitor, PD98059, and the PI3K inhibitor, LY294002. In mice, CRMP4 overexpression was found to facilitate tumor growth and metastasis (42). Taken together, these results imply that CRMP4 can be controlled and that the modulation of CRMP4 expression at the cellular level may affect cancer-cell radiation sensitivity.

Although further biochemical studies are required to characterize the physiological properties of CRMP4 as an important player in radiation-resistant colon cancer cells, our findings suggest that radioresistance-associated CRMP4 might be related to the $\mathrm{Ca}^{2+}$-mediated apoptotic pathway and that CRMP4 may be an attractive target for radiation-mediated or -combined colon cancer therapy.

\section{Acknowledgements}

Not applicable.

\section{Funding}

The present study was supported by the National Research Foundation of Korea (NRF) grant funded by the Korean government (MSIT) (no. 2020R1A2C2010321) and the KRIBB Research Initiative Program.

\section{Availability of data and materials}

The datasets used and/or analyzed during the current study are available from the corresponding author on reasonable request. 


\section{Authors' contributions}

SYP, JTK, BYK, and HGL designed the study; SYP, JTK, YSH, ESP, HRY, HJ, and KEB performed the experiments; SYP, JTK, HJ, SRY, and HJC contributed essential reagents or tools; SYP, JTK, HJC, BYK, SRY, and HGL analyzed the data; SYP, JTK, HJC, and HGL wrote the manuscript. All authors critically revised the manuscript and approved the final version of the manuscript.

\section{Ethics approval and consent to participate}

Not applicable.

\section{Patient consent for publication}

Not applicable.

\section{Competing interests}

The authors declare that they have no competing interests.

\section{References}

1. Begg AC, Stewart FA and Vens C: Strategies to improve radiotherapy with targeted drugs. Nat Rev Cancer 11: 239-253, 2011.

2. Habibullah G, Gul R, Cassum S and Elahi R: Experiences of the breast cancer patients undergoing radiotherapy at a Public Hospital Peshawar Pakistan. Asia Pac J Oncol Nurs 5: 184-194, 2018.

3. Baskar R, Dai J, Wenlong N, Yeo R and Yeoh KW: Biological response of cancer cells to radiation treatment. Front Mol Biosci 1: 24, 2014

4. Ponnusamy R, Lebedev AA, Pahlow S and Lohkamp B: Crystal structure of human CRMP-4: Correction of intensities for lattice-translocation disorder. Acta Crystallogr D Biol Crystallogr 70: 1680-1694, 2014.

5. Ponnusamy R and Lohkamp B: Insights into the oligomerization of CRMPs: Crystal structure of human collapsin response mediator protein 5. J Neurochem 125: 855-868, 2013.

6. Deo RC, Schmidt EF, Elhabazi A, Togashi H, Burley SK and Strittmatter SM: Structural bases for CRMP function in plexin-dependent semaphorin3A signaling. EMBO J 23: 9-22, 2004.

7. Minturn JE, Fryer HJ, Geschwind DH and Hockfield S: TOAD-64, a gene expressed early in neuronal differentiation in the rat, is related to unc-33, a C. elegans gene involved in axon outgrowth. J Neurosci 15: 6757-6766, 1995.

8. Nagai J, Kitamura Y, Owada K, Yamashita N, Takei K, Goshima Y and Ohshima T: Crmp4 deletion promotes recovery from spinal cord injury by neuroprotection and limited scar formation. Sci Rep 5: 8269, 2015.

9. Hiroshima Y, Nakamura F, Miyamoto H, Mori R, Taniguchi K, Matsuyama R, Akiyama H, Tanaka K, Ichikawa Y, Kato S, et al Collapsin response mediator protein 4 expression is associated with liver metastasis and poor survival in pancreatic cancer. Ann Surg Oncol 20 (Suppl 3): S369-S378, 2013.

10. Tan M, Ma S, Huang Q, Hu K, Song B and Li M: GSK-3 $\alpha / \beta$-mediated phosphorylation of CRMP-2 regulates activity-dependent dendritic growth. J Neurochem 125: 685-697, 2013.

11. Matsunuma R, Chan DW, Kim BJ, Singh P, Han A, Saltzman AB, Cheng C, Lei JT, Wang J, Roberto da Silva L, et al: DPYSL3 modulates mitosis, migration, and epithelial-to-mesenchymal transition in claudin-low breast cancer. Proc Natl Acad Sci USA 115: E11978-11987, 2018.

12. Zhou W, Xie P, Pang M, Yang B, Fang Y, Shu T, Liu C, Wang X, Zhang L, Li S and Rong L: Upregulation of CRMP4, a new prostate cancer metastasis suppressor gene, inhibits tumor growth in a nude mouse intratibial injection model. Int J Oncol 46: 290-298, 2015
13. Gerencser AA, Chinopoulos C, Birket MJ, Jastroch M, Vitelli C, Nicholls DG and Brand MD: Quantitative measurement of mitochondrial membrane potential in cultured cells: Calcium-induced de- and hyperpolarization of neuronal mitochondria. J Physiol 590: 2845-2871, 2012.

14. Molkentin JD: Calcineurin, mitochondrial membrane potential, and cardiomyocyte apoptosis. Circ Res 88: 1220-1222, 2001.

15. Orrenius S, Zhivotovsky B and Nicotera P: Regulation of cell death: The calcium-apoptosis link. Nat Rev Mol Cell Biol 4: 552-565, 2003.

16. Heise N, Palme D, Misovic M, Koka S, Rudner J, Lang F, Salih HR, Huber SM and Henke G: Non-selective cation channel-mediated $\mathrm{Ca}^{2+}$-entry and activation of $\mathrm{Ca}^{2+} /$ calmodulin-dependent kinase II contribute to G2/M cell cycle arrest and survival of irradiated leukemia cells. Cell Physiol Biochem 26: 597-608, 2010.

17. Meyn RE, Stephens LC, Voehringer DW, Story MD, Mirkovic N and Milas L: Biochemical modulation of radiation-induced apoptosis in murine lymphoma cells. Radiat Res 136: 327-334, 1993.

18. Porporato PE, Filigheddu N,Pedro JMB, Kroemer G and Galluzzi L: Mitochondrial metabolism and cancer. Cell Res 28: 265-280, 2018.

19. Zhang Z, Majava V, Greffier A, Hayes RL, Kursula P and Wang KK: Collapsin response mediator protein-2 is a calmodulin-binding protein. Cell Mol Life Sci 66: 526-536, 2009.

20. Wang Y, Brittain JM, Wilson SM and Khanna R: Emerging roles of collapsin response mediator proteins (CRMPs) as regulators of voltage-gated calcium channels and synaptic transmission. Commun Integr Biol 3: 172-175, 2010.

21. Park SY, Lee SJ, Cho HJ, Kim JT, Yoon HR, Lee KH, Kim BY, Lee Y and Lee HG: Epsilon-globin HBE1 enhances radiotherapy resistance by down-regulating BCL11A in colorectal cancer cells. Cancers (Basel) 11: 498, 2019.

22. Yokoi K, Yamashita K, Ishii S, Tanaka T, Nishizawa N, Tsutsui A, Miura H, Katoh H, Yamanashi T, Naito M, et al: Comprehensive molecular exploration identified promoter DNA methylation of the CRBP1 gene as a determinant of radiation sensitivity in rectal cancer. Br J Cancer 116: 1046-1056, 2017.

23. Martin M: Cutadapt removes adapter sequences from high-throughput sequencing reads. EMBnet J 17: 10-12, 2011.

24. Dobin A, Davis CA, Schlessinger F, Drenkow J, Zaleski C, Jha S, Batut P, Chaisson $M$ and Gingeras TR: STAR: Ultrafast universal RNA-seq aligner. Bioinformatics 29: 15-21, 2013.

25. Anders S, Pyl PT and Huber W: HTSeq-a Python framework to work with high-throughput sequencing data. Bioinformatics 31: $166-169,2015$.

26. Robinson MD, McCarthy DJ and Smyth GK: edgeR: A Bioconductor package for differential expression analysis of digital gene expression data. Bioinformatics 26: 139-140, 2010.

27. Smaili SS, Hsu YT, Carvalho AC, Rosenstock TR, Sharpe JC and Youle RJ: Mitochondria, calcium and pro-apoptotic proteins as mediators in cell death signaling. Braz J Med Biol Res 36: 183-190, 2003.

28. Romero-Garcia S and Prado-Garcia H: Mitochondrial calcium: Transport and modulation of cellular processes in homeostasis and cancer (Review). Int J Oncol 54: 1155-1167, 2019.

29. Schmidt EF and Strittmatter SM: The CRMP family of proteins and their role in Sema3A signaling. Adv Exp Med Biol 600: 1-11, 2007.

30. Alabed YZ, Pool M, Ong Tone S, Sutherland C and Fournier AE: GSK3 beta regulates myelin-dependent axon outgrowth inhibition through CRMP4. J Neurosci 30: 3635-3643, 2010.

31. Ohtani-Kaneko R: Crmp4-KO mice as an animal model for investigating certain phenotypes of autism spectrum disorders. Int J Mol Sci 20: 2485, 2019.

32. Huang QX, Xiao CT, Chen Z, Lu MH, Pang J, Di JM, Luo ZH and Gao X: Combined analysis of CRMP4 methylation levels and CAPRA-S score predicts metastasis and outcomes in prostate cancer patients. Asian J Androl 20: 56-61, 2018.

33. Guo $\mathrm{H}$ and Xia B: Collapsin response mediator protein 4 isoforms (CRMP4a and CRMP4b) have opposite effects on cell proliferation, migration, and invasion in gastric cancer. BMC Cancer 16: 565, 2016.

34. Sato S, Nakamura F, Hiroshima Y, Nagashima Y, Kato I, Yamashita N, Goshima Y and Endo I: Caerulein-induced pancreatitis augments the expression and phosphorylation of collapsin response mediator protein 4 . J Hepatobiliary Pancreat Sci 23: 422-431, 2016.

35. Oya H, Kanda M, Sugimoto H, Shimizu D, Takami H, Hibino S, Hashimoto R, Okamura Y, Yamada S, Fujii T, et al: Dihydropyrimidinase-like 3 is a putative hepatocellular carcinoma tumor suppressor. J Gastroenterol 50: 590-600, 2015. 
36. Crompton M: The mitochondrial permeability transition pore and its role in cell death. Biochem J 341: 233-249, 1999.

37. Ravagnan L, Roumier T and Kroemer G: Mitochondria, the killer organelles and their weapons. J Cell Physiol 192: 131-137, 2002.

38. Halestrap AP, Connern CP, Griffiths EJ and Kerr PM Cyclosporin A binding to mitochondrial cyclophilin inhibits the permeability transition pore and protects hearts from ischaemia/reperfusion injury. Mol Cell Biochem 174: 167-172, 1997.

39. Rademaker J, Schöder H, Ariaratnam NS, Strauss HW, Yahalom J, Steingart R and Oeffinger KC: Coronary artery disease after radiation therapy for Hodgkin's lymphoma: Coronary $\mathrm{CT}$ angiography findings and calcium scores in nine asymptomatic patients. AJR Am J Roentgenol 191: 32-37, 2008.
40. Tagliarino C, Pink JJ, Dubyak GR, Nieminen AL and Boothman DA: Calcium is a key signaling molecule in beta-lapachone-mediated cell death. J Biol Chem 276: 19150-19159, 2001.

41. Zhou Y, Li R, Yu H, Wang R and Shen Z: microRNA-130a is an oncomir suppressing the expression of CRMP4 in gastric cancer. Onco Targets Ther 10: 3893-3905, 2017.

42. Chen S, Zhang X, Peng J, Zhai E, He Y, Wu H, Chen C, Ma J, Wang $\mathrm{Z}$ and Cai S: VEGF promotes gastric cancer development by upregulating CRMP4. Oncotarget 7: 17074-17086, 2016.

(i) $($ ) This work is licensed under a Creative Commons Attribution-NonCommercial-NoDerivatives 4.0 International (CC BY-NC-ND 4.0) License. 